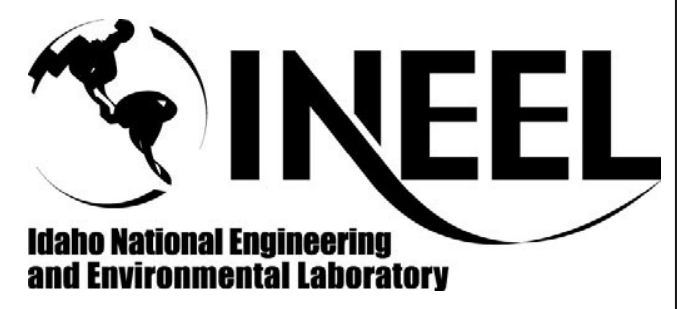

INEEL/CON-01-01491

PREPRINT

Heat Transfer Enhancement For Finned-Tube Heat Exchangers With Vortex Generators: Experimental And Numerical Results

\author{
J. E. O'Brien \\ M. S. Sohal \\ T. D. Foust \\ P. C. Wallstedt
}

August 18, 2002

$12^{\text {th }}$ International Heat Transfer Conference

This is a preprint of a paper intended for publication in a journal or proceedings. Since changes may be made before publication, this preprint should not be cited or reproduced without permission of the author. This document was prepared as an account of work sponsored by an agency of the United States Government. Neither the United States Government nor any agency thereof, or any of their employees, makes any warranty, expressed or implied, or assumes any legal liability or responsibility for any third party's use, or the results of such use, of any information, apparatus, product or process disclosed in this report, or represents that its use by such third party would not infringe privately owned rights. The views expressed in this paper are not necessarily those of the U.S. Government or the sponsoring agency. 


\title{
Heat transfer enhancement for finned-tube heat exchangers with vortex generators: experimental and numerical results
}

\author{
J. E. O’Brien, M. S. Sohal, T. D. Foust, P. C. Wallstedt \\ Idaho National Engineering and Environmental Laboratory (INEEL) \\ Idaho Falls, ID 83415-3885
}

\begin{abstract}
A combined experimental and numerical investigation is under way to investigate heat transfer enhancement techniques that may be applicable to large-scale air-cooled condensers such as those used in geothermal power applications. The research is focused on whether air-side heat transfer can be improved through the use of finsurface vortex generators (winglets,) while maintaining low heat exchanger pressure drop. A transient heat transfer visualization and measurement technique has been employed in order to obtain detailed distributions of local heat transfer coefficients on model fin surfaces. Pressure drop measurements have also been acquired in a separate multiple-tube row apparatus. In addition, numerical modeling techniques have been developed to allow prediction of local and average heat transfer for these low-Reynolds-number flows with and without winglets.

Representative experimental and numerical results presented in this paper reveal quantitative details of local fin-surface heat transfer in the vicinity of a circular tube with a single delta winglet pair downstream of the cylinder. The winglets were triangular (delta) with a 1:2 height/length aspect ratio and a height equal to $90 \%$ of the channel height. Overall mean fin-surface Nusselt-number results indicate a significant level of heat transfer enhancement (average enhancement ratio 35\%) associated with the deployment of the winglets with oval tubes.

Pressure drop measurements have also been obtained for a variety of tube and winglet configurations using a single-channel flow apparatus that includes four tube rows in a staggered array. Comparisons of heat transfer and pressure drop results for the elliptical tube versus a circular tube with and without winglets are provided. Heat transfer and pressure-drop results have been obtained for flow Reynolds numbers based on channel height and mean flow velocity ranging from 700 to 6500 .
\end{abstract}

\section{1. introduction}

Large air-cooled condensers such as those used in binary-cycle geothermal power plants require the use of finned tubes in order to increase heat transfer surface area on the air side. Induced-draft fans are mounted on top of the units to draw air upward through several rows of long individually finned tubes. The condenser units can be very large, representing as much as $50 \%$ of the capital cost of these power plants. In addition, the power required to operate the fans represents a significant parasitic house load, reducing the net power production of the plant. Research under way at the INEEL has been undertaken with the aim of devising viable heat transfer enhancement strategies for application to geothermal air-cooled condensers and similar devices. In order to broaden the scope of our investigation, we have formed an international team of researchers under a grant from the Japanese New Energy and Industrial Development Organization (NEDO). The team includes scientists from Yokohama National University (YNU) and from the Indian Institute of Technology (IIT), Kanpur. Researchers at INEEL have published results of high-resolution single-tube local heat transfer measurements and corresponding numerical predictions (O'Brien and Sohal, 2000a, 2000b, Foust et al., 2001, O'Brien et al., 2001). Overall heat transfer and pressure-drop results have been obtained for tube bundles at YNU using a single-blow technique. In addition, flow visualization and PIV flow field measurements have been obtained at YNU (Kawai et al., 2001), documenting whole-field measurements of the complex flows around finned tubes with vortex generators. These measurements have revealed that a drastic shrinkage of the wake region behind a circular cylinder can be achieved by a unique arrangement of vortex generators beside the tubes. Finally, numerical techniques have been developed at IIT Kanpur (Prabhakar et al., 2001) to enable evaluation of the heat transfer and fluid flow performance of finned-tube/winglet combinations.

Longitudinal vortices are generated naturally in fin-tube heat exchanger passages by the interaction of the flow velocity profile with the heat exchanger tube. These naturally occurring vortices are called horseshoe vortices. Longitudinal vortices can also be created through the use of winglet vortex generators mounted or punched into 
the fin surfaces. Jacobi and Shah (1995) provide an excellent review of heat transfer enhancement through the use of longitudinal vortices. Various winglet shapes have been studied. Results presented in the present paper are restricted to delta winglets, deployed in conjunction with an elliptical tube. The specific winglet deployment geometries considered in this study are based on configurations studied numerically for low Reynolds numbers by Chen et al. (2000) for a single winglet pair located near the upstream end of an oval tube. Additional fundamental studies of heat transfer associated with longitudinal vortex generators are available in the literature. An investigation of the mechanisms of heat transfer enhancement associated with deltawing vortex generators was performed by Torii et al. (1994).

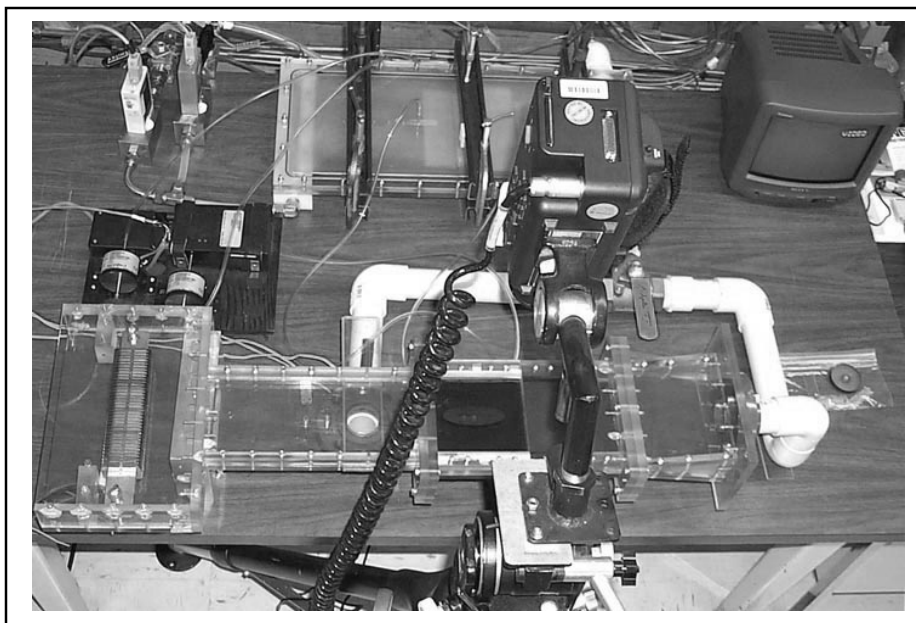

Figure 1. Photograph of experimental setup for local heat transfer (bottom) and pressure drop (top).

\section{2. the experiments}

The heat transfer experiments were performed in a narrow rectangular duct designed to simulate a single passage of a fin-tube heat exchanger. The duct height is $1.016 \mathrm{~cm}$ and the duct width-to-height ratio, $\mathrm{W} / \mathrm{H}$, is 11.25. The single elliptical tube had an aspect ratio of 3:1 and a major axis half-length, a/H, equal to 4.33. The triangular (delta) winglets had a 1:2 height/length aspect ratio and were oriented at a 30-degree angle to the flow. The height of the winglets, $h_{w}$, was $90 \%$ of the channel height. The test section length was $27.94 \mathrm{~cm}(11.0 \mathrm{in}$.), yielding $\mathrm{L} / \mathrm{H}=27.5$. A flow-development section with $\mathrm{L} / \mathrm{H}=30$ was located upstream of the test section.

In order to enable thermal visualization of the test section bottom surface (representing the fin surface), the top wall of the flow duct in the vicinity of the circular tube was formed by a calcium fluoride $\left(\mathrm{CaF}_{2}\right)$ window with dimensions: $12.7 \mathrm{~cm} \times 12.7 \mathrm{~cm} \times 6 \mathrm{~mm}$ (5 in. $\times 5$ in. x 0.24 in.). The $\mathrm{CaF}_{2}$ windows are essentially transparent in the wavelength range of sensitivity $(3.6$ to $5 \mu \mathrm{m})$ of the imaging infrared camera. The test section bottom surface (polycarbonate) was painted black using ultra-flat black paint in order to achieve a surface emissivity very close to 1.0. A photograph of the experimental setup is shown in Fig. 1.

A transient heat transfer measurement technique was employed for obtaining detailed local heat transfer measurements on the model fin surface. Inlet air is heated to a desired temperature using a feedback-controlled finned-element air heater. The heated air initially flows through a bypass line until the desired air temperature and flow rate is established. The air is then suddenly diverted through the test section by changing the position of a 3-way valve. Using this technique, the room-temperature fin/tube model is suddenly exposed to a uniformly heated airflow, initiating a heat conduction transient in the test section substrate. Local surface temperatures on the substrate increase at a rate that is dependent on the value of the local heat transfer coefficient. This transient localized heating is quantitatively recorded using a precision imaging infrared camera. Values of local heat transfer coefficients can then be determined from an inverse heat conduction analysis. Infra-red thermography has several advantages over thermochromic liquid crystals for surface temperature mapping, including wide available temperature range, high spatial resolution, excellent thermal resolution, and full-field direct digital data acquisition and processing. Air flow rate is controlled over the range of about $1.51 \times 10^{-3}$ to $14.0 \times 10^{-3} \mathrm{~kg} / \mathrm{s}$. These flow rates correspond to a duct-height Reynolds number $\left(\operatorname{Re}_{\mathrm{H}}=\rho \mathrm{UH} / \mu=\dot{m} / \mu \mathrm{W}\right)$ range of $670-6300$ with a duct height of $1.016 \mathrm{~cm}$ and a duct width-to-height ratio, $\mathrm{W} / \mathrm{H}$, of 11.25 .

Representative local heat transfer results will be presented in this paper for the case of a circular tube plus winglets. Mean heat transfer and pressure-drop results for an elliptical tube with and without winglets and for a single delta-winglet pair will also be presented,. The winglets had a 1:2 height/length aspect ratio and a height equal to $90 \%$ of the channel height. This height was chosen rather than the full channel height in order to avoid damage to the windows. The winglets were machined from polycarbonate and were bonded to the test surface. 
A separate single-channel multiple-tube-row apparatus was fabricated for evaluating the pressure-drop performance of the various tube and winglet configurations studied in the heat transfer experiments (see Fig. 1, top). The oval and circular tubes were designed to have the same cross-sectional flow area. Dried and filtered shop air enters the flow channel from a slot located $24 \mathrm{~cm}$ upstream of the tube bundle. The flow channel dimensions were $0.254 \mathrm{~cm}$ high $\times 22.86 \mathrm{~cm}$ wide. A row of six pressure taps was drilled along the channel centerline upstream and downstream of a four-tube row staggered array of either circular or elliptical tubes, with or without winglets. The tube array simulates a single passage in a plate-fin heat exchanger. Pressure drop was measured using a precision differential pressure transducer; air flow rates were obtained from a precision massflow meter.

Two techniques were used for the pressure-drop tests: steady-flow and blow-down. Steady-flow tests were performed by establishing a steady airflow using a flow-control valve, then acquiring a large number of averages of both flow rate and pressure-drop at a fixed flow rate. Blow-down tests were performed by charging the air compressor storage tank to a predetermined pressure with no flow, then discharging the tank through the system while continuously monitoring instantaneous flow rate and pressure drop. The air compressor was disabled during the blow-down. Blow-down testing allowed pressure-drop measurements to be obtained over a much broader flow range (both higher and lower flows) than steady-flow tests. It also provided a complete pressuredrop versus flow rate data set over the entire flow rate range of interest in a single test. Results obtained with the steady-state technique and the blow-down technique were in excellent agreement.

In order to obtain heat transfer coefficients from the surface temperatures measured during the transient heatup of the test section, the bottom surface of the test section is assumed to behave locally as a one-dimensional semi-infinite solid undergoing a step change in surface heat transfer coefficient. The time-dependent surface temperature for a semi-infinite solid subjected to this boundary condition is given by:

$$
\theta=1-\exp \left(\gamma^{2}\right) \operatorname{erfc}(\gamma), \quad \quad \quad \quad \quad \quad \quad=\frac{T(0, t)-T_{i}}{T_{\infty}-T_{i}} ; \gamma=\frac{h \sqrt{\alpha t}}{k}=\frac{h \sqrt{t}}{\sqrt{\rho c k}}
$$

This equation represents the relationship between heat transfer coefficient, $h$, and surface temperature, $T(0, t)$, measured at a specific time, $\mathrm{t}$, after the start of the test. It must be solved iteratively for $\gamma$ at each pixel location (78,000 pixels). Each pixel temperature is thereby to a heat transfer coefficient..

Local heat transfer results are presented in terms of heat transfer coefficient. Average heat transfer is presented in terms of Nusselt number based on channel height, $\mathrm{Nu}_{\mathrm{H}}=\mathrm{hH} / \mathrm{k}$, parameterized by the Reynolds number based on channel height, $\mathrm{Re}_{\mathrm{H}}=\rho \mathrm{UH} / \mu=\mathrm{m} / \mu \mathrm{W}$. Pressure-drop results are presented in terms of friction factor, defined as:

$$
f=\frac{\Delta P \rho}{G^{2} / 2\left(4 L / D_{h}\right)} \quad \text { where } \quad D_{h}=\frac{4 L A_{\min }}{A}
$$

In the definition of friction factor, $\mathrm{G}$ is the mass flux at the minimum flow area, $\Delta \mathrm{P}$ is the pressure drop across the tube bundle, and $\mathrm{L}$ is the axial length of the tube bundle. $\mathrm{A}_{\min }$ is the minimum flow cross-sectional area, and A is the total heat transfer surface area. Friction factors are parameterized using the Reynolds number based on hydraulic diameter, $\mathrm{Re}_{\mathrm{Dh}}=\mathrm{GD}_{\mathrm{h}} / \mu$. Note that this friction factor definition does not include any entrance or exit effects. Only core friction is considered, since the measured pressure drop only corresponds to core friction. Estimates of the experimental uncertainties of the Reynolds numbers, heat transfer coefficients, and friction factors presented in this paper have been obtained based on constant-odds, 95\% confidence level (Moffatt, 1988). Typical values are 3\% for Reynolds number, $15 \%$ for heat transfer coefficient, and $5 \%$ for friction factor.

\section{3. numerical model}

The geometry of the computational domain was based on the experimental test section. A block-structured meshing technique was utilized. The computational domain matches the test section exactly with the exception that symmetry conditions were utilized about the test section centerline both in the vertical and horizontal directions. This effectively reduces the computational domain to $1 / 4$ of the test section domain and saves 
considerable computational resources. In order to obtain accurate determinations of surface heat transfer coefficients, a very fine grid spacing is required for the channel height. For this work three grids were used to verify grid-independent results. The three grids had 20, 24, and 30 cells across the channel height (H/2). This corresponds to cell vertical heights of $0.25 \mathrm{~mm} ., 0.21 \mathrm{~mm}$ and $0.167 \mathrm{~mm}$ respectively. This grid refinement in turn leads to very large computational domains, since fine grid spacing in one direction necessitates fine spacing in the other two directions in order to maintain reasonable cell aspect ratios. All grids were constructed so that the maximum aspect ratio never exceeds 7:1, thereby minimizing numerical diffusion. Boundary conditions were set to accurately reflect the conditions in the test section. The inlet condition was set as a velocity inlet with a specified mean flow velocity. A parabolic profile was used to represent the fully developed velocity profile from the $\mathrm{L} / \mathrm{H}=30$ flow development portion of the test section.

The governing conservation equations were solved using the commercial computational fluid dynamics code FLUENT. A second-order upwind discretization scheme was used for higher-order accuracy. A PRESTO (PREssure STaggering Option, Patankar, 1980) scheme was used to account for the tube wall curvature in the computational domain. A Pressure-Implicit with Splitting of Operators (PISO) pressure-velocity coupling scheme is utilized. It is part of the SIMPLE (Patankar, 1980) family of algorithms and is based on the higher degree of the approximate relation between the corrections for pressure and velocity.

All runs were made on a Sun Enterprise 5000 Unix machine with 14 Ultrasparc II processors. For the $\mathrm{Re}_{\mathrm{H}}=$ 500 case, runs were made for the three grids $(20,24$ and 30 vertical cell) on a single processor using an unsteady solution technique. Computer run times to 1.0 second after the initiation of the transient were approximately 36 hours for the 30 -vertical-cell grid.

\section{4. results}

Representative results of both experimentally measured and numerically predicted local heat transfer distributions are presented in Fig. 2 for low-Reynolds number $\left(\mathrm{Re}_{\mathrm{H}}=670\right)$ flow around a circular cylinder with vortex-generating winglets located downstream of the cylinder. The rationale for locating the winglets downstream of the cylinder is based on the desire to improve heat transfer in the wake region. Local heat transfer results obtained from the numerical model are in good agreement with the experimental results. The addition of winglets yields a reduction in the size of the low-heat-transfer wake region and also provides localized heat transfer enhancement in the vicinity of the winglets. Peak local heat transfer coefficients in the vicinity of the winglets are similar to the peak values observed in the cylinder stagnation region. A distinct

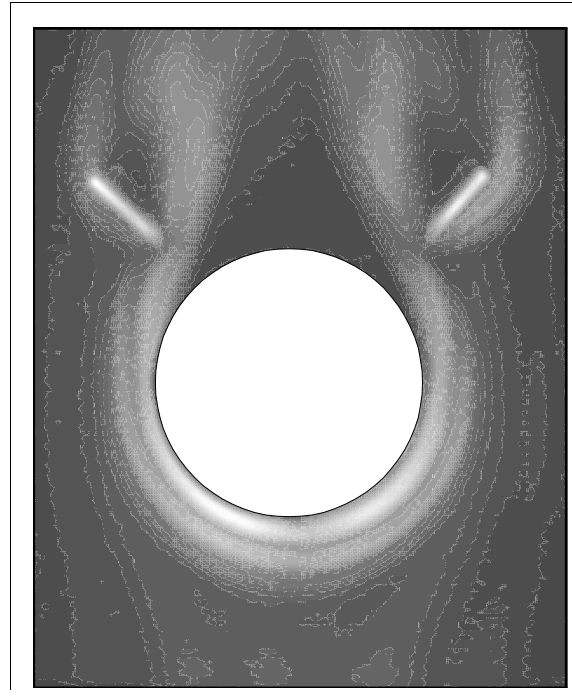

(a)

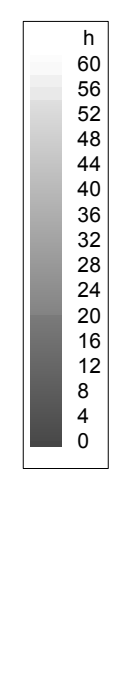

Figure 2. Local distributions of heat transfer coefficient, $\mathrm{h}\left(\mathrm{W} / \mathrm{m}^{2} \mathrm{~K}\right)$ at $\mathrm{Re}_{\mathrm{H}}=670$; (a) experimental results, (b) numerical predictions.
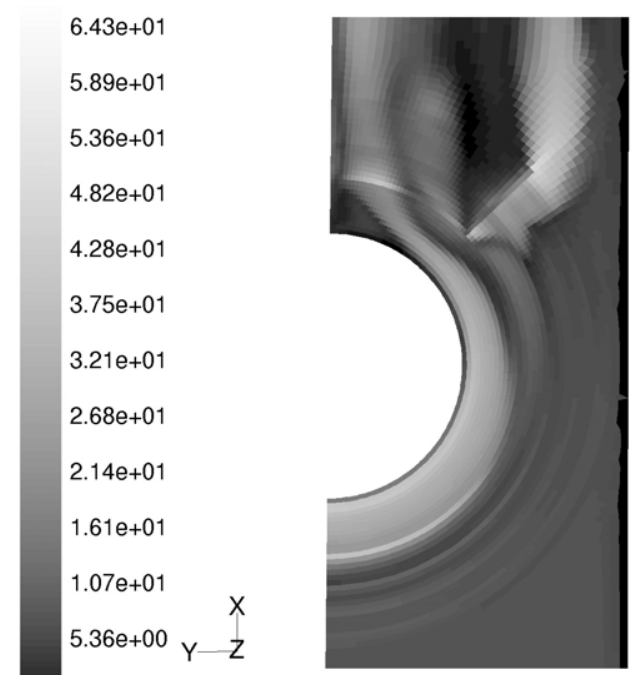

(b) 

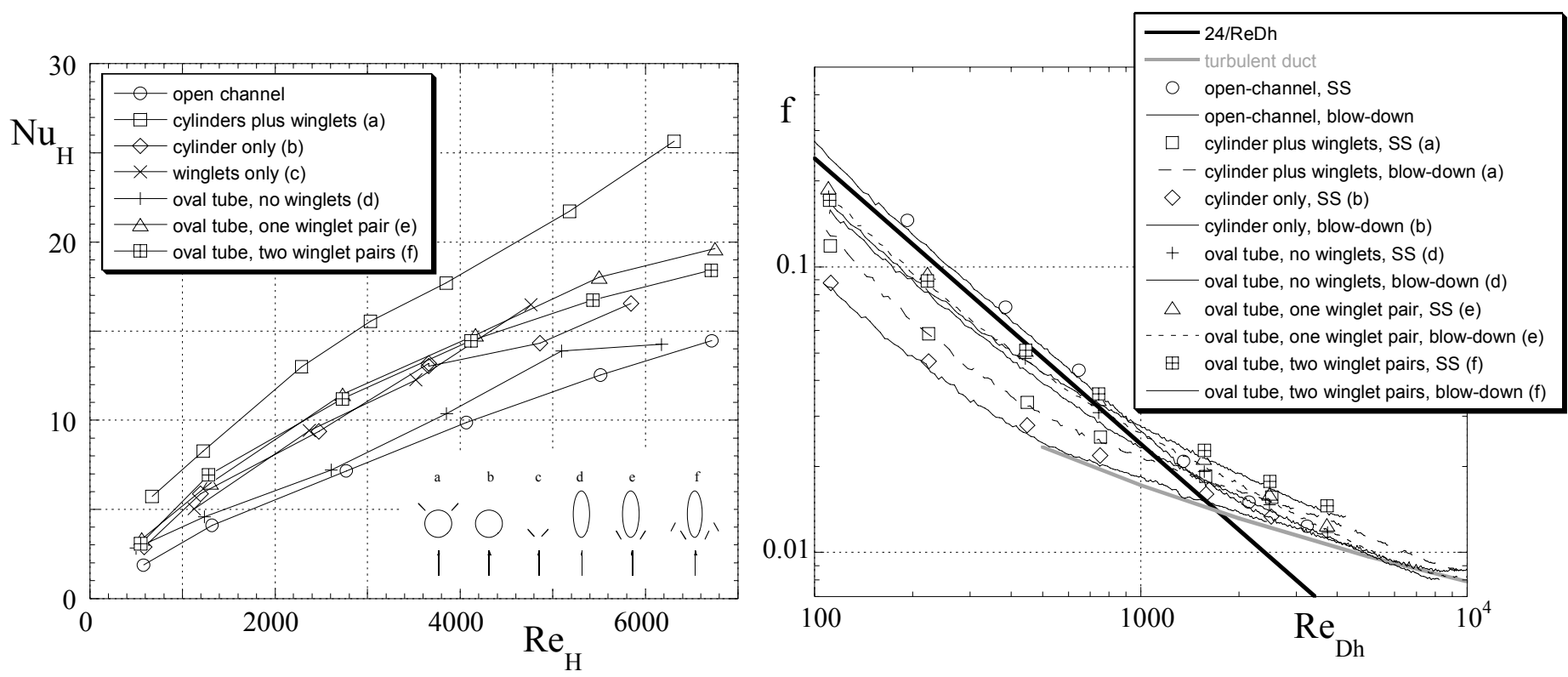

Figure 3. Mean Nusselt numbers and friction factors for seven geometries studied.

double peak in local heat transfer coefficient is visible in the cylinder stagnation region at this Reynolds number (O’Brien and Sohal, 2000a).

Mean fin-surface heat transfer coefficients have been calculated based on the single-tube local heat transfer results for seven flow configurations. Results of these calculations are presented in Fig. 3. A small schematic of each flow configuration is shown in the figure. Highest heat transfer coefficients were observed for the case of a circular tube plus winglets with the winglets located on the downstream side of the cylinder, oriented at a $45^{\circ}$ angle to the flow. The cases of oval tube plus one pair of winglets and oval tube plus two pairs of winglets yielded similar mean heat transfer results. The addition of the single winglet pair to the oval-tube geometry yielded significant heat transfer enhancement, averaging 38\% higher than the oval-tube, no-winglet case. Mean Nusselt numbers for the cases of a circular tube without winglets and a single delta-winglet pair with no tube yielded similar results. Heat transfer results for the oval tube without winglets were quite low. Lowest heat transfer coefficients, as expected, were produced by the open-channel configuration.

In order to fully assess the performance of any of these flow configurations, pressure-drop behavior must be also considered. Results of the pressure-drop measurements obtained with the single-channel, multiple-tube-row pressure drop apparatus are also presented in Fig. 3 in terms of friction factor versus Reynolds number based on hydraulic diameter, as defined in Eqn. (2). Based on this definition, at low Reynolds numbers, highest friction factors were observed for the open channel, followed by the oval-tube cases and finally by the circular-tube cases. Actual pressure drop magnitudes are in the opposite order. The friction factor results reflect the fact that the minimum-area mass flux, $G$, is successively higher for the oval-tube cases and the circular-tube cases for a specified total mass flow rate (note that $\mathrm{G}^{2}$ appears in the denominator of the friction factor definition). Openchannel data agree well with the theoretical value of $24 / \mathrm{Re}_{\mathrm{Dh}}$ for laminar flow in a parallel-plate channel. The friction factor data for all cases tend to converge at higher (turbulent) Reynolds numbers, approaching the Petukov correlation for turbulent-flow friction factor. Friction factor results for cases with winglets are higher than their respective baseline cases since the only quantity that is different in calculating those friction factors is the magnitude of the pressure drop. It should be noted that because the mean heat transfer results were obtained from the single-tube heat transfer tests and the friction factor results were obtained from a multiple-tube-row configuration, the heat transfer and friction factor results do not correspond to identical flow situations. This is why the mean heat transfer results have not been converted to $\mathrm{j}$-factors for presentation on the same graph as the friction factors, as is standard practice for presentation of heat exchanger results. We are in the process of developing a new apparatus that will provide both overall heat transfer and pressure-drop results for an entire tube bundle. 


\section{5. conclusions}

An experimental study has been performed to examine the local and mean heat transfer performance of circular and elliptical tubes with vortex-generator winglets. Heat transfer measurements were obtained using a transient technique in which a heated airflow is suddenly introduced to the test section. High-resolution local fin-surface temperatures were acquired at several times after initiation of the transient using an imaging infrared camera. Corresponding local fin-surface heat transfer coefficients were then calculated from a locally applied one-dimensional semi-infinite inverse heat conduction model. Pressure drop measurements have also been obtained for similar elliptical-tube and winglet geometries using a separate single-channel, multiple-tube-row pressure-drop apparatus. The pressure-drop apparatus includes four tube rows in a staggered array. Heat transfer and pressure-drop results were obtained over a Reynolds number range based on duct height of approximately $600-6500$. Supporting numerical calculations have also been performed.

Local heat transfer results clearly indicate areas of heat transfer enhancement associated with both the primary vortex and the corner, horseshoe-type vortices produced by each winglet. Evaluation of mean fin-surface heat transfer coefficients indicated that the addition of the single winglet pair to the oval-tube geometry yielded significant heat transfer enhancement, averaging 38\% higher than the oval-tube, no-winglet case. The corresponding increase in friction factor was very modest, less than $10 \%$ at $\mathrm{Re}_{\mathrm{Dh}}=500$ and less than $5 \%$ at $\mathrm{Re}_{\mathrm{Dh}}$ $=5000$. Highest mean heat transfer coefficients were observed for the case of a circular tube plus winglets with the winglets located on the downstream side of the cylinder, oriented at a $45^{\circ}$ angle to the flow.

\section{6. acknowledgement}

This work was sponsored by the U.S. Department of Energy, Geothermal Program. The Idaho National Engineering and Environmental Laboratory is operated by Bechtel, Babcock and Wilcox Idaho, LLC under contract number DE-AC07-99ID13727. The authors would also like to acknowledge the support received from the Japanese New Energy and Industrial Technology Development Organization, under research grant \#99EF1.

\section{References}

Chen, Y., Fiebig, M., and Mitra, N. K., "Heat Transfer Enhancement of Finned Oval Tubes with Staggered Punched Longitudinal Vortex Generators," Int. J. Heat Mass Transfer, Vol. 43, pp. 417-435, 2000.

Foust, T. D., O'Brien, J. E., and Sohal, M. S., "Numerical and Experimental Methods for Heat Transfer Enhancement for Finned-Tube Heat Exchangers with Oval Tubes," 2001 ASME National Heat Transfer Conference, Anaheim, June 2001, paper no. NHTC01-12363.

Jacobi, A. M., and Shah, R. K., "Heat Transfer Surface Enhancement through the Use of Longitudinal Vortices: A Review of Recent Progress," Experimental Thermal and Fluid Science, Vol. 11, pp. 295-309, 1995.

Kawai, R., Nishino, and Torii, K, "PIV Measurement of 3D Velocity Distribution around Finned Tubes with Vortex Generators," $4^{\text {th }}$ International Symposium on Particle Image Velocimetry, Gottingen, Germany, Sept., 2001.

Moffatt, R. J., "Describing the Uncertainties in Experimental Results," Experimental Thermal and Fluid Science, Vol. 1, pp. 3-17, 1988.

O'Brien, J. E., and Sohal, M. S., "Local Heat Transfer for Finned-Tube Heat Exchangers using Oval Tubes," Proceedings, 2000 ASME National Heat Transfer Conference, Pittsburgh, paper no. NHTC2000-12093, August, 2000a.

O'Brien, J. E., and Sohal, M. S., "Heat Transfer Enhancement for Finned-tube Heat Exchangers with Winglets," Proceedings, 2000 ASME International Congress and Exposition, Orlando, HTD-Vol. 365/PID-Vol. 4, pp. 137-146, November, 2000b.

O'Brien, J. E., Sohal, M. S., and Wallstedt, P. C., "Local Heat Transfer and Pressure Drop for Finned-Tube Heat Exchangers using Oval Tubes and Vortex Generators," Proceedings, 2001 ASME International Congress and Exposition, Orlando, November, 2001.

Patankar, S.V., "Numerical Heat Transfer and Fluid Flow",Hemisphere Publishing Corporation, 1980.

Prabhakar, V., Biswas, G., and Eswaran, V.,"Numerical Prediction of Heat Transfer in a Channel with a Built-in Oval Tube and Two Different Vortex Generators," Numerical Heat Transfer, 2001.

Torii, K., Nishino, K., and Nakayama, K., "Mechanism of Heat Transfer Augmentation by Longitudinal Vortices in a Flat Plate Boundary Layer," Proceedings, Tenth Int. Heat Transfer Conf., Vol. 6, pp. 123-128, Hemisphere, New York, 1994. 